\title{
In situ UV-VIS Detection of the Association of Water-Soluble Anionic Porphyrin and Aromatic Bases in Aqueous Solution at High Tempeatures Using a Capillary Flow Hydrothermal Reactor System
}

\author{
Kunio KaWAmura \\ Department of Applied Chemistry, Graduate School of Engineering, Osaka Prefecture University, \\ Gakuen-cho 1-1, Sakai, Osaka 599-8531, Japan
}

\begin{abstract}
The association between anionic water-soluble porphyrin and aromatic heterocyclic bases has been investigated to demonstrate the usefulness of a new in situ UV-VIS monitoring method of hydrothermal reactions. Spectral and absorbance changes in the presence of bases were possible to be detected by the new method at temperatures up to $150^{\circ} \mathrm{C}$. The association constants $\left(K_{\text {ass, }, 1}\right)$ were determined from the absorbance-base concentration curves. The logarithmic values of $K_{\text {ass }, 1}$ were proportional to the number of rings of the bases, but this relationship became ambiguous beyond $100^{\circ} \mathrm{C}$. This fact indicates that stacking between porphyrin and bases does indeed become weak at high temperatures.
\end{abstract}

(Received February 17, 2003; Accepted June 12, 2003)

Hydrothermal reactions are becoming important in both fundamental and practical areas. For example, it is widely believed that hydrothermal environments played an important role in chemical evolution under the primitive earth conditions. ${ }^{1}$ Several types of monitoring techniques using batch and flow reactors have been developed to study reaction behaviors of hydrothermal processes. ${ }^{2-7}$ One difficulty of monitoring hydrothermal reactions is that the reaction rates under the hydrothermal conditions increase with increasing temperature. Thus, monitoring hydrothermal reactions at the millisecond second time range is frequently required. ${ }^{7,8}$ Besides, in situ spectral measurements are important to detect reactants and interactions under the hydrothermal conditions. To eliminate the influence of the decomposition of chemical species during monitoring a target reaction, the observation of the reaction should be performed within such a short time range. While in situ techniques have become popular using Raman and FT-IR spectroscopy, ${ }^{2,4}$ UV-VIS spectroscopy is not yet generally practical. ${ }^{3,5}$ Thus, we have developed a new monitoring method using a flow reactor, which enables in situ UV-VIS spectrophotometric measurement in aqueous solution at high temperatures, in the time range $0.08-3.2 \mathrm{~s}$ at temperatures up to $300^{\circ} \mathrm{C}$ (Capillary Flow Hydrothermal (CFH) UV-VIS spectrophotometry). ${ }^{9}$ Results suggest that the $\mathrm{CFH}$ system will be useful to obtain both equilibrium and kinetic information on the hydrothermal reactions. Another interest concerning hydrothermal chemistry is focused on how biologically important interactions such as hydrophobic interaction act at elevated to high temperatures. However, there are few experimental investigations on these interactions. Thus, in the present study, the scope of the CFH method was investigated; the method was applied to monitoring the association between porphyrin and heterocyclic aromatic bases. ${ }^{10}$ The association constants were successfully determined by the CFH method at elevated temperatures and the thermodynamic parameters were estimated. This study demonstrates that the $\mathrm{CFH}$ method is useful and potent as a general technique for the measurements of UV-VIS absorbance and absorption spectra at high temperatures.

\section{Experimental}

\section{Reagents and apparatus}

All reagents used were of analytical grade. A water-soluble porphyrin 5,10,15,20-tetrakis(4-sulfonatophenyl)porphine (TPPS 4 ), 2,2'-bipyridyl (BPY), and 2,4,6-tris(2-pyridyl)-1,3,5triazine (TPTZ) were purchased from Dojindo, Japan, and $2,2^{\prime}: 6^{\prime}, 2^{\prime \prime}$-terpyridine (TPY) was obtained from Wako Pure Chemical Industries, Japan. Solutions containing $2.09 \times 10^{-5} \mathrm{M}$ $\mathrm{TPPS}_{4}, 0.01 \mathrm{M}$ borate buffer, $0.1 \mathrm{M} \mathrm{NaCl}, 0-1.25 \times 10^{-3} \mathrm{M}$ base $(\mathrm{pH}=9.0)$ were prepared.

The CFH system for hydrothermal reactions was set up as described in the previous study. ${ }^{9}$ The capillary tubing used was of $0.1 \mathrm{~mm}$ inner diameter and $34.0 \mathrm{~cm}$ effective length; the effective volume exposed at high temperatures was $2.67 \times 10^{-3}$ $\mathrm{cm}^{3}$. The residence time during which the sample is exposed at a high temperature can be regulated by changing the flow rate and the size of capillary. Here, the flow rate was adjusted to $0.25 \mathrm{~mL} / \mathrm{min}$, so the residence time was $0.64 \mathrm{~s}$. The residence time is sufficiently longer than the time required for heating up the sample solution $(\mathrm{ca} .40 \mathrm{~ms}))^{7,9}$ The temperature was controlled at $25-150^{\circ} \mathrm{C}$ with $0.1 \%$ error and the pressure was controlled at $10 \mathrm{M} \mathrm{Pa}$. The sample solution was injected in the $\mathrm{CFH}$ system through a $0.1 \mathrm{~mL}$ loop injector, and absorbance and absorption spectra were recorded. Absorption spectra at $25^{\circ} \mathrm{C}$ were also measured using a $0.1 \mathrm{~cm}$ quartz cell on a Shimadzu UV 240 spectrophotometer to compare the absorbance-base concentration curves. 


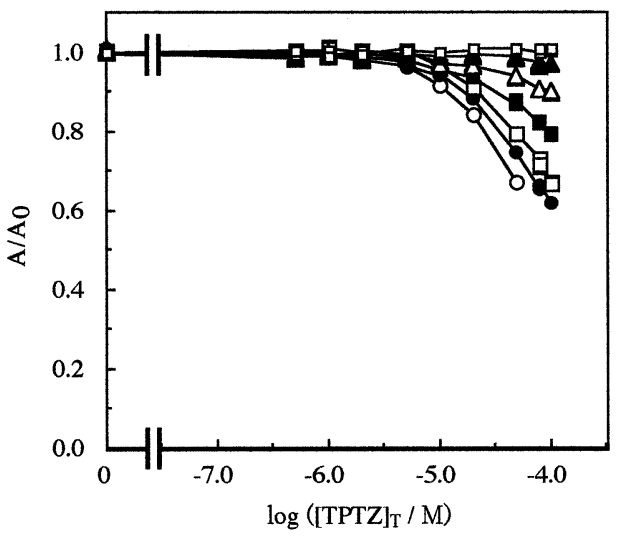

Fig. 1 Relative absorbance $\left(A / A_{0}\right)-\log [\mathrm{TPTZ}]$ curves for $\mathrm{TPPS}_{4}$ with TPTZ at $25-150^{\circ} \mathrm{C}$. Conditions: $\left[\mathrm{TPPS}_{4}\right]=2.09 \times 10^{-5} \mathrm{M}$, $[\mathrm{NaCl}]=0.1 \mathrm{M},\left[\mathrm{Na}_{2} \mathrm{~B}_{4} \mathrm{O}_{7}\right]=0.01 \mathrm{M}, \mathrm{pH}=9.0$. Temperature: open circles and closed circles, $25^{\circ} \mathrm{C}$; open squares, $50^{\circ} \mathrm{C}$; closed squares, $75^{\circ} \mathrm{C}$; open triangles, $100^{\circ} \mathrm{C}$; closed triangles, $125^{\circ} \mathrm{C}$; small open squares, $150^{\circ} \mathrm{C}$. The measurements were performed using the $\mathrm{CFH}$ system at $25-150^{\circ} \mathrm{C}$ and using the conventional spectrophotometer at $25^{\circ} \mathrm{C}$ (closed circles).

\section{Results and Discussion}

In situ measurement of UV-VIS absorbance and absorption spectra

The absorbance at $413 \mathrm{~nm}$, the wavelength of maximum absorption at Soret band of $\mathrm{TPPS}_{4}$, was monitored in the presence of several bases at $25-150^{\circ} \mathrm{C}$. The absorbance changes were successfully measured using the $\mathrm{CFH}$ system. Each sample was injected 3-8 times to obtain accurate data. Absorbance-base concentration curves are shown in Fig. 1 for the case of TPTZ; obviously the absorbance change fairly decreased with increasing temperature. The absorption spectra are also observed as shown in Fig. 2, which indicates the differences between porphyrin and its associate with bases. The decrease of absorbance change at elevated temperatures suggests that the association between TPPS $_{4}$ and base becomes weaker at elevated temperatures. Although the monitoring using the $\mathrm{CFH}$ method is possible up to $300^{\circ} \mathrm{C},{ }^{9}$ the measurements were performed at up to $150^{\circ} \mathrm{C}$ in this study since no change in absorbance was observed beyond $150^{\circ} \mathrm{C}$. This fact indicates that $\mathrm{TPPS}_{4}$ is stable at $0.64 \mathrm{~s}$ residence time when exposed at high temperatures. Furthermore, it was also confirmed that bases were stable during the $\mathrm{CFH}$ measurements; the absorption spectra of these bases at 260-300 nm were constant at different residence times and temperatures. Besides, to test the reliability of the absorbance change monitored using the CFH system, the absorption spectra and absorbance were measured using a $0.1 \mathrm{~cm}$ cell on a conventional UV-VIS spectrophotometer. The absorbance changes of $\mathrm{TPPS}_{4}$ determined using the $\mathrm{CFH}$ system at $25^{\circ} \mathrm{C}$ (closed circles in Fig. 1) are consistent with those measured using the conventional spectrophotometer (open circles). However, the absorbance-base concentration curves using the conventional system are shifted down about 0.2 unit of $\log$ [base] to the lower base concentration. Such differences will be discussed later.

\section{Association constants of $\mathrm{TPPS}_{4}$ and bases}

According to the absorbance-base concentration curves, the association constants $\left(K_{\text {ass }, 1}\right)$ between $\mathrm{TPPS}_{4}$ and bases were

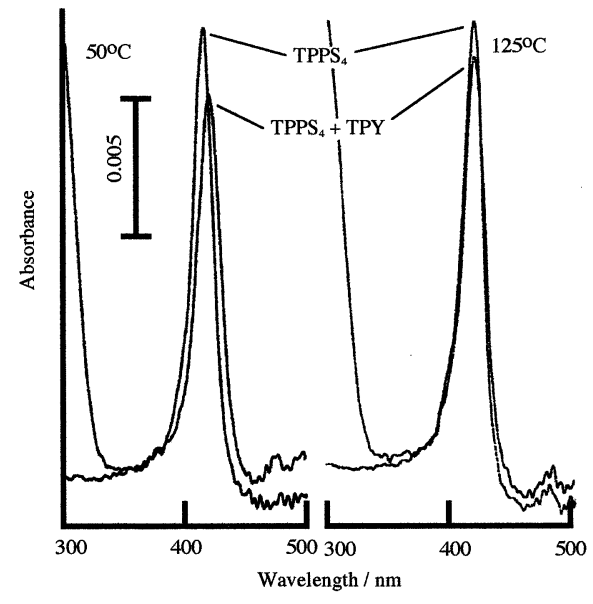

Fig. 2 Spectral change of $\mathrm{TPPS}_{4}$ in the presence of TPY at $50^{\circ} \mathrm{C}$ and $125^{\circ} \mathrm{C}$ detected using the $\mathrm{CFH}$ system. Conditions: [TPPS 4 ] $=$ $2.09 \times 10^{-5} \mathrm{M},[\mathrm{TPY}]=5.0 \times 10^{-4} \mathrm{M},[\mathrm{NaCl}]=0.1 \mathrm{M},\left[\mathrm{Na}_{2} \mathrm{~B}_{4} \mathrm{O}_{7}\right]=$ $0.01 \mathrm{M}, \mathrm{pH}=9.0$.

calculated. While one step association is assumed for the cases of TPY and BPY, two step association is assumed for the case of TPTZ, as shown in Eqs. (1) and (2). ${ }^{10}$

$$
\begin{aligned}
& \text { Porphyrine }+ \text { Base } \rightleftharpoons \text { Porphyrine } \cdots \text { Base } \\
& \text { Porphyrine } \cdots \text { Base }+ \text { Base } \rightleftharpoons \text { Porphyrine } \cdots(\text { Base })_{2}
\end{aligned}
$$

Calculations to determine the values of $K_{\text {ass, } 1}$ were carried out using a nonlinear fitting on a computer program Mathematica version 2.2.2 (Table 1).

The values of $K_{\text {ass, } 1}$ determined using the $\mathrm{CFH}$ system was 1.55 times smaller in average than those determined using the conventional spectrophotometer. This difference reflects the influence of dilution of injected samples in the CFH system. That is to say, the difference $(\Delta K)$ between the association constants determined using these methods is expressed in Eq. (3),

$$
\begin{array}{r}
\log \left(K_{\text {ass }, 1}(\text { batch method })\right)=\log \left(K_{\text {ass }, 1}(\text { CFH system })\right) \\
+\log \Delta K
\end{array}
$$

Although the influence of dilution to the reaction rates needs not be considered for most cases of pseudo-first-order reactions, it is necessary to evaluate the influence of dilution for pseudosecond-order and highly complicated reactions. The influence of the dilution of the injected samples in the $\mathrm{CFH}$ system can be estimated from the following considerations. For the reaction shown in Eq. (4), the apparent equilibrium constant $\left(K_{\text {app }}\right)$ is defined in Eq. (5):

$$
\begin{aligned}
& \mathrm{A}+\mathrm{B} \rightleftharpoons \mathrm{AB} \\
& K_{\text {app }}=[\mathrm{AB}]^{\prime} /\left([\mathrm{A}]^{\prime}[\mathrm{B}]^{\prime}\right)
\end{aligned}
$$

where $\mathrm{A}$ and $\mathrm{B}$ are reactants and $\mathrm{AB}$ is the product. Here, $[\mathrm{A}]^{\prime}$, $[\mathrm{B}]^{\prime}$, and $[\mathrm{AB}]^{\prime}$ indicate the concentrations of the sample prepared for the injections into the $\mathrm{CFH}$ system. The value of $K_{\text {app, } 1}$ is promptly calculated from the experimental absorbance-concentration curves with values of $[\mathrm{A}]^{\prime},[\mathrm{B}]^{\prime}$, and $[\mathrm{AB}]^{\prime}$. However, the real concentrations of the chemical species in the $\mathrm{CFH}$ system are diluted by a factor of $\phi$, as shown in Eqs. 
Table 1 Association constants between TPPS $_{4}$ and bases at 25 $-125^{\circ} \mathrm{C}^{\mathrm{a}}$

\begin{tabular}{cccc}
\hline & \multicolumn{3}{c}{$\log \left(K_{\text {ass }, 1} / \mathrm{M}^{-1}\right)$} \\
$T /^{\circ} \mathrm{C}$ & TPTZ & TPY & BPY \\
\hline 25 & $4.3 \pm 0.1$ & $3.5 \pm 0.1$ & $2.4 \pm 0.1$ \\
50 & $4.2 \pm 0.1$ & $3.3 \pm 0.1$ & $2.3 \pm 0.1$ \\
75 & $3.9 \pm 0.1$ & $3.1 \pm 0.1$ & $2.3 \pm 0.1$ \\
100 & $3.5 \pm 0.1$ & $2.8 \pm 0.1$ & $2.1 \pm 0.1$ \\
125 & $2.9 \pm 0.1$ & $2.5 \pm 0.1$ & $1.9 \pm 0.1$ \\
$25^{\mathrm{b}}$ & $4.6 \pm 0.1$ & $3.7 \pm 0.1$ & $2.5 \pm 0.1$ \\
\hline
\end{tabular}

a. The association constants were determined using the $\mathrm{CFH}$ system. b. The association constants were determined using a conventional UV-VIS spectrophotometer with a $0.1 \mathrm{~cm}$ quartz cell.

$(6 a-c)$

$$
\begin{aligned}
& {[\mathrm{A}]=\phi[\mathrm{A}]^{\prime}} \\
& {[\mathrm{B}]=\phi[\mathrm{B}]^{\prime}} \\
& {[\mathrm{AB}]=\phi[\mathrm{AB}]^{\prime}}
\end{aligned}
$$

where $\phi$ is dilution factor. Thus, the real value of the equilibrium constant $\left(K_{\text {real }}\right)$ for the reaction (4) is given by Eq. (7).

$$
K_{\text {real }}=[\mathrm{AB}] /([\mathrm{A}][\mathrm{B}])
$$

Then, $K_{\text {app }}$ is given by $K_{\text {real }}$ and $\phi$.

$$
\begin{aligned}
& K_{\text {real }}=(1 / \phi) K_{\text {app }} \\
& \log K_{\text {real }}=\log K_{\text {app }}-\log \phi
\end{aligned}
$$

Thus, the value of $(1 / \phi)$ is equated to that of $\Delta K$ since $K_{\text {real }}$ and $K_{\text {app }}$ correspond to $K_{\text {ass }, 1}$ (batch method) and $K_{\text {ass }, 1}(\mathrm{CFH}$ system), respectively. The influence of dilution in the $\mathrm{CFH}$ system was evaluated for the first time by the present consideration. The magnitude of $\log \Delta K(0.19)$ in average should be independent of the type of reactions. Furthermore, it is possible for this value to be used for the determination of equilibrium constants for other reactions as long as one uses the same CFH system with the same flow rate. The value of the present $\Delta K$ was not as large as was expected; this fact indicates that equilibrium constants at extremely high temperatures can be determined just, by using the correction factor $(\phi)$. This is obviously convenient for determining equilibrium constants at high temperatures. This advantage is probably due to the fact that the present system applies the fused-silica capillary tubing with laminar flow. Accordingly, the present system is practical for the UV-VIS measurements at high temperature as long as the influence of dilution is properly treated.

The magnitude of $K_{\text {ass }, 1}$ decreased with temperature in the order TPTZ > TPY > BPY, which is consistent with the trend found in the previous study. ${ }^{10}$ The fact that the logarithmic values of $K_{\text {ass }, 1}$ are proportional to the number of aromatic rings (N) of the bases is consistent with the previous results obtained at a low temperature (Fig. 3). However, the trend becomes ambiguous at higher temperatures, over $100^{\circ} \mathrm{C}$; this may be due to the fact that the absorbance changes were notably small. These values could have given difficulty to determining $K_{\text {ass, } 1}$ at over $100^{\circ} \mathrm{C}$. The relationship between $\log K_{\text {ass }, 1}$ and $\mathrm{N}$ indicates

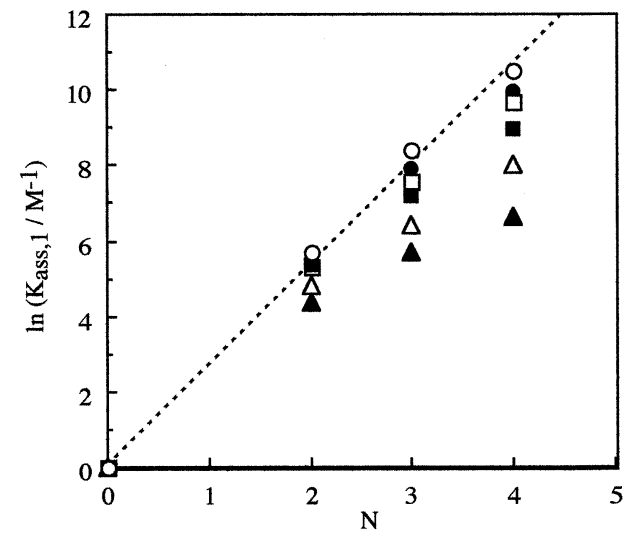

Fig. 3 The relationship between logarithmic values of $K_{\text {ass }, 1}$ and the number of heterocyclic rings of the bases. Open circles and closed circles, $25^{\circ} \mathrm{C}$; open squares, $50^{\circ} \mathrm{C}$; closed squares, $75^{\circ} \mathrm{C}$; open triangles, $100^{\circ} \mathrm{C}$; closed triangles, $125^{\circ} \mathrm{C}$. The measurements were performed using the $\mathrm{CFH}$ system at $25-150^{\circ} \mathrm{C}$ and using the conventional spectrophotometer at $25^{\circ} \mathrm{C}$ (open circles).

that the stacking of TPPS $_{4}$ with bases by hydrophobic and/or $\pi$ $\pi$ interactions decreases with increasing temperature. Although not much attention has been focused on biologically important but weak interactions such as hydrophobic interaction and hydrogen bonding at elevated to high temperatures, this study quantitatively displayed the decrease of stacking at elevated temperatures. Stacking between $\mathrm{TPPS}_{4}$ and the aromatic bases would be a typical example of association that is caused by hydrophobic and $\pi-\pi$ interactions. Thus, decrease of stacking between porphyrin and the bases supports our general conclusion that stacking within biologically important molecules such as nucleic acids could be reduced beyond $100^{\circ} \mathrm{C}$.

Since the logarithmic values of $K_{\text {ass, } 1}$ decrease with increasing $T^{-1}$, the temperature dependence of the values of $K_{\text {ass, } 1}$ was evaluated to calculate the magnitudes of enthalpy $\left(\Delta H_{\text {ass }, 1}\right)$ and entropy $\left(\Delta S_{\text {ass, } 1}\right)$ changes. The values of $\Delta H_{\text {ass, } 1}\left(\mathrm{~kJ} \mathrm{~mol}^{-1}\right)$ decrease in the order BPY $(-8 \pm 2)>$ TPY $(-18 \pm 4)>$ TPTZ $(-24 \pm 5)$ and the values of $\Delta S_{\text {ass, } 1}\left(\mathrm{~J} \mathrm{~mol}^{-1} \mathrm{~K}^{-1}\right)$ decrease in the order BPY $(19 \pm 5)>$ TPY $(6 \pm 11)>\operatorname{TPTZ}(5 \pm 14)$. The negative enthalpy changes support the proposal that an attraction force such as $\pi-\pi$ interaction exists between TPPS $_{4}$ and bases. ${ }^{11}$

The present study demonstrated the usefulness and applicability of the proposed technique for the measurements of UV-VIS absorption spectra and absorbance in aqueous solution at elevated to high temperatures. Based on the temperature dependence of $K_{\text {ass, },}$, the reality of weakness of hydrophobic and $\pi-\pi$ interactions at high temperatures was visualized at temperatures over $100^{\circ} \mathrm{C}$.

\section{Acknowledgements}

The Engineering Laboratory and Workshop Center, Osaka Prefecture University, facilitated this work by generously preparing parts of the system. This research was supported by the Mazda Foundation's Research Grant 2000. 


\section{References}

1. "Special Issue-Marine Hydrothermal Systems and the Origin of Life", ed. N. G. Holm, Origins Life Evol. Biosphere, 1992, 22, 5 - 242; K. Kawamura, Viva Origino, 2000, $28,129$.

2. D. A. Masten. B. R. Foy, D. M. Harradine, and R. B. Dyer, J. Phys. Chem., 1993, 97, 8557.

3. G. E. Bennett and L. P. Johnston, J. Phys. Chem., 1994, 98 , 441.

4. M. L. Kieke, J. W. Schoppelrei, and T. B. Brill, J. Phys. Chem., 1996, 100, 7455; T. B. Brill, J. Phys. Chem. A, 2000, 104, 4343.
5. J. L. Ferry and M. A. Fox, J. Phys. Chem. A, 1998, 102, 3705 .

6. K. Kawamura, Nippon Kagaku Kaishi, 1998, 255.

7. K. Kawamura, Chem. Lett., 1999, 125; K. Kawamura, Bull. Chem. Soc. Jpn., 2000, 73, 1805.

8. K. Kawamura, Nucleic Acids Symp. Ser., 1999, 42, 289; K. Kawamura and M. Yukioka, Thermochimica Acta, 2001, 375, 9; K. Kawamura, Chem. Lett., 2001, 1120; K. Kawamura, Bull. Chem. Soc. Jpn., 2003, 76, 153.

9. K. Kawamura, Anal. Sci., 2002, 18, 715.

10. K. Kawamura, H. Kasahara, S. Igarashi, and $\mathrm{T}$. Yotsuyanagi, Chem. Lett., 1987, 2365.

11. L. F. Newcomb and S. H. Gellman, J. Am. Chem. Soc., 1994, 116, 4993. 